\title{
Performance test of an automated moment tensor determination system for the future "Tokai" earthquake
}

\author{
Eiichi Fukuyama* and Douglas S. Dreger
}

National Research Institute for Earth Science and Disaster Prevention, Department of Geology and Geophysics, University of California, Berkeley

(Received November 26, 1999; Revised April 27, 2000; Accepted May 19, 2000)

\begin{abstract}
We have investigated how the automated moment tensor determination (AMTD) system using the FREESIA/ KIBAN broadband network is likely to behave during a future large earthquake. Because we do not have enough experience with a large $(M>8)$ nearby earthquake, we computed synthetic waveforms for such an event by assuming the geometrical configuration of the anticipated Tokai earthquake and several fault rupture scenarios. Using this synthetic data set, we examined the behavior of the AMTD system to learn how to prepare for such an event. For our synthetic Tokai event data we assume its focal mechanism, fault dimension, and scalar seismic moment. We also assume a circular rupture propagation with constant rupture velocity and dislocation rise time. Both uniform and heterogeneous slip models are tested. The results show that performance depends on both the hypocentral location (i.e. unilateral vs. bilateral) and the degree of heterogeneity of slip. In the tests that we have performed the rupture directivity appears to be more important than slip heterogeneity. We find that for such large earthquakes it is necessary to use stations at distances greater than $600 \mathrm{~km}$ and frequencies between 0.005 to $0.02 \mathrm{~Hz}$ to maintain a point-source assumption and to recover the full scalar seismic moment and radiation pattern. In order to confirm the result of the synthetic test, we have analyzed the 1993 Hokkaido Nansei-oki $\left(\mathbf{M}_{\mathbf{J}} 7.8\right)$ and the 1995 Kobe (MJ 7.2$)$ earthquakes by using observed broadband waveforms. For the Kobe earthquake we successfully recovered the moment tensor by using the routinely used frequency band (0.01-0.05 Hz displacements). However, we failed to estimate a correct solution for the Hokkaido Nansei-oki earthquake by using the same routine frequency band. In this case, we had to use the frequencies between 0.005 to $0.02 \mathrm{~Hz}$ to recover the moment tensor, confirming the validity of the synthetic test result for the Tokai earthquake.
\end{abstract}

\section{Introduction}

The broadband FREESIA/KIBAN network developed by the National Research Institute for Earth Science and Disaster Prevention (NIED) (e.g. Fukuyama et al., 1996) provides high quality, continuous broadband waveform data in realtime. At each station, a three-component broadband seismometer (STS-1) with a three-component strong motion velocity meter (VSE-311/355) are deployed. Using these waveform data we have constructed an automated moment tensor determination (AMTD) system, which in routine operation has proven to be stable and reliable (Fukuyama et al., 1998). This algorithm estimates the seismic moment tensor of moderate to large earthquakes within 20 minutes of their occurrence, and reliable solutions are obtained for events with magnitude greater than 3.5 and good signal-to-noise quality. These solutions are automatically disseminated via the World Wide Web ${ }^{1}$ (Fukuyama et al., 1999).

The object of this paper is to evaluate the performance of the AMTD method in the analysis of likely waveforms from a magnitude 8 earthquake occurring in and near Japan. Because such a large nearby earthquake has not occurred

\footnotetext{
*Present address: National Research Institute for Earth Science and Disaster Prevention, 3-1 Tennodai, Tsukuba, Ibaraki 305-0006, Japan.

${ }^{1}$ http://argent.geo.bosai.go.jp

Copy right $($ C The Society of Geomagnetism and Earth, Planetary and Space Sciences (SGEPSS); The Seismological Society of Japan; The Volcanological Society of Japan; The Geodetic Society of Japan; The Japanese Society for Planetary Sciences.
}

since the development of the FREESIA/KIBAN network it is necessary to assess the performance of the system using synthetic seismograms. This analysis is doubly important considering that the moment tensor information that is now routinely determined by NIED will be expected to be of great importance following a future large earthquake. Moreover, soon after the large earthquake, estimation of slip distribution on the fault plane would be very useful for the purpose of strong ground motion evaluation. To do this, rapid moment tensor estimation becomes a fundamental information.

The seismic moment tensor approach that we employ utilizes long-period waves in the 0.01 to $0.05 \mathrm{~Hz}$ pass band. In this pass band it is recognized that synthetic seismograms used to fit the data must be complete in terms of near and intermediate field terms. Near-field terms are routinely observed in the waveforms of moderate local events (e.g. Dreger and Helmberger, 1990 and 1991). For large earthquakes these near-field effects together with the integrated nature of distributed fault slip posses a problem in the simple data processing scheme and point-source assumption used in rapid, regional distance moment tensor methods. Fig. 1 illustrates a near-field seismogram for the 1992 Landers, California earthquake $\left(\mathrm{M}_{\mathrm{W}} 7.3\right)$ recorded at a distance of $3 \mathrm{~km}$. The near-field effects observed in this seismogram would cause a breakdown in the routine moment tensor processing as it currently is implemented. The static offset and the ramp shaped seismograms would not be well modeled by point- 
Table 1. Description of models used.

\begin{tabular}{lcccl}
$\begin{array}{c}\text { Model } \\
\text { name }\end{array}$ & $\begin{array}{c}\text { Hypocenter } \\
\text { location }\end{array}$ & $\begin{array}{c}\text { Rupture } \\
\text { velocity }\end{array}$ & $\begin{array}{c}\text { Rise } \\
\text { time }\end{array}$ & $\begin{array}{c}\text { Slip } \\
\text { distribution }\end{array}$ \\
\hline UNI-MID & A & $3.0 \mathrm{~km} / \mathrm{s}$ & $1 \mathrm{~s}$ & constant \\
UNI-NW & B & $3.0 \mathrm{~km} / \mathrm{s}$ & $1 \mathrm{~s}$ & constant \\
HET-MID & A & $3.0 \mathrm{~km} / \mathrm{s}$ & $1 \mathrm{~s}$ & two asperities \\
HET-NW & B & $2.0 \mathrm{~km} / \mathrm{s}$ & $1 \mathrm{~s}$ & two asperities \\
SAG-UNI-MID & $\mathrm{C}$ & $3.0 \mathrm{~km} / \mathrm{s}$ & $1 \mathrm{~s}$ & constant \\
SAG-HET-NW & D & $2.0 \mathrm{~km} / \mathrm{s}$ & $1 \mathrm{~s}$ & two asperities \\
\hline
\end{tabular}

Table 2. Velocity structure used in this analysis.

\begin{tabular}{cccccc}
\hline $\begin{array}{c}\text { Thickness } \\
(\mathrm{km})\end{array}$ & $\begin{array}{c}P \text {-wave velocity } \\
(\mathrm{km} / \mathrm{s})\end{array}$ & $\begin{array}{c}S \text {-wave velocity } \\
(\mathrm{km} / \mathrm{s})\end{array}$ & $\begin{array}{c}\text { Density } \\
\left(\mathrm{kg} / \mathrm{m}^{3}\right)\end{array}$ & $Q_{\alpha}$ & $Q_{\beta}$ \\
\hline 3.0 & 5.50 & 3.14 & 2300 & 600 & 300 \\
15.0 & 6.00 & 3.55 & 2400 & 600 & 300 \\
15.0 & 6.70 & 3.83 & 2800 & 600 & 300 \\
67.0 & 7.80 & 4.46 & 3200 & 600 & 300 \\
- & 8.00 & 4.57 & 3300 & 600 & 300 \\
\hline
\end{tabular}

\section{Landers Recorded at Lucerne Valley}

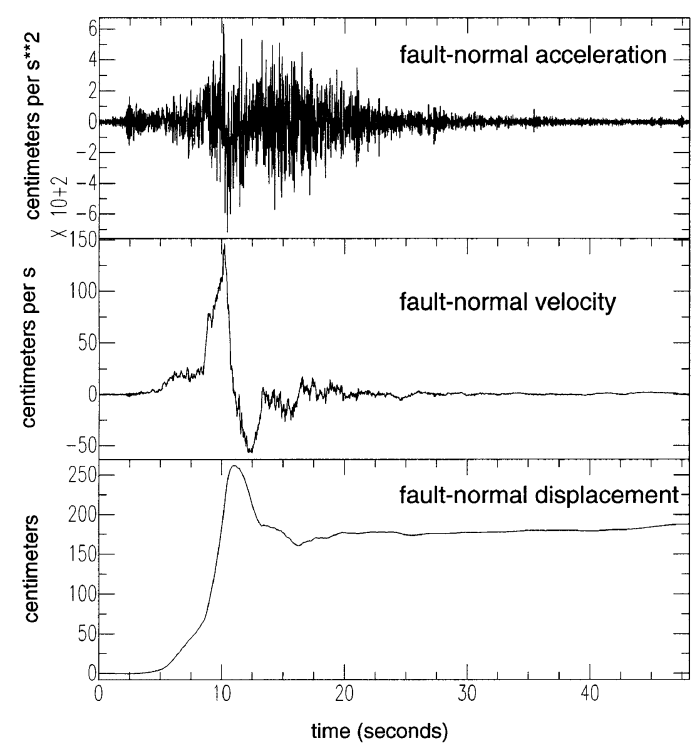

Fig. 1. Near-field seismogram (fault normal component) of the 1992 Landers, California, earthquake recorded at a distance of $3 \mathrm{~km}$.

source synthetics. It has been shown, however, that at greater distances it is possible to obtain robust source parameters for this event. For a magnitude 8.2 earthquake the near-field effects on the waveforms would be expected to be observed at several hundred kilometers as will be demonstrated in our

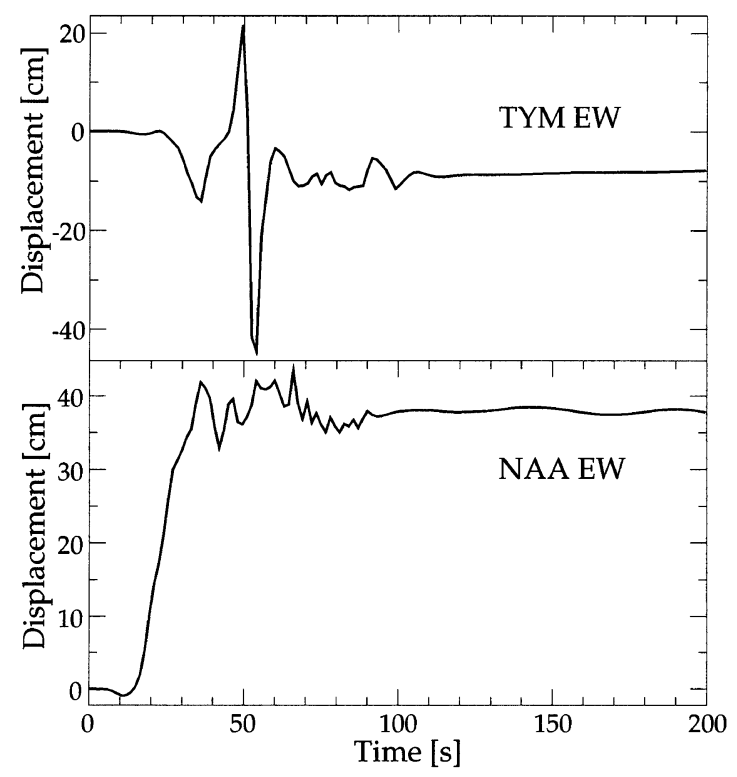

Fig. 2. Example of computed waveforms at TYM and NAA by assuming uniform slip with mid bottom hypocenter based on Ishibashi model. East-west components are shown at two similar hypocentral distance stations.

synthesis of fault rupture (Fig. 2). This will clearly be problematic and the question we wish to address in this study is what needs to be done to improve performance for this important class of earthquake.

Of course, moment tensors obtained by using waveforms 


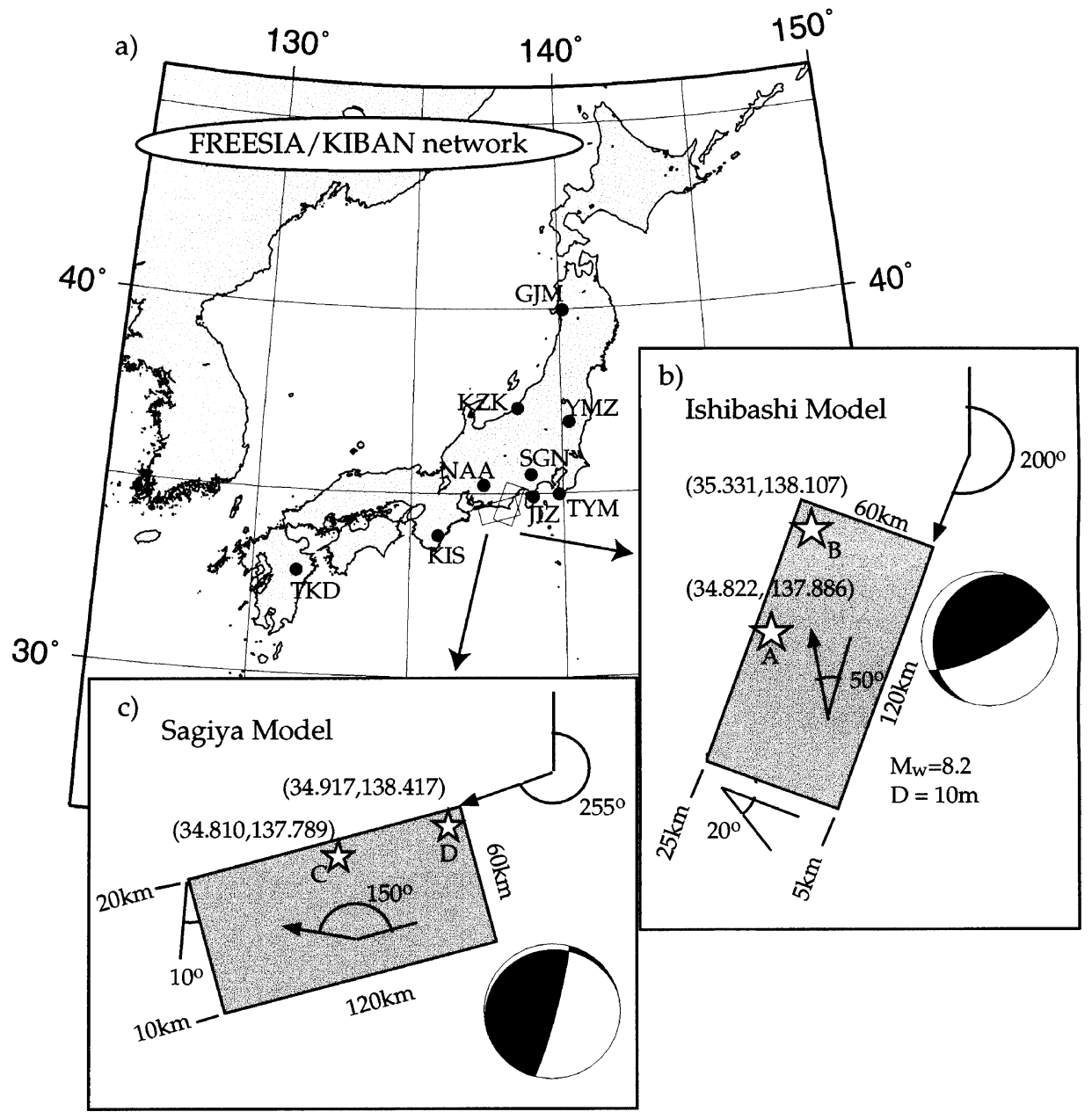

Fig. 3. a) Station distribution of the FREESIA / KIBAN broadband seismic network. The assumed fault models: b) Ishibashi model and c) Sagiya model are shown with their dimension, mechanism etc. We assumed two hypocenters in each model (A, B and C, D), whose locations are also shown.

Table 3. Station selection, filter coefficients, and zero offset adjustment.

\begin{tabular}{cclcl}
\hline & $\begin{array}{c}\text { Hypocentral } \\
\text { distance }\end{array}$ & \multicolumn{1}{c}{$\begin{array}{c}\text { Used } \\
\text { stations }\end{array}$} & $\begin{array}{c}\text { Filter } \\
\text { pass-band }\end{array}$ & $\begin{array}{c}\text { Time-shift } \\
\text { adjustment }\end{array}$ \\
\hline Group 1 & $100 \mathrm{~km}$ & JIZ, NAA, SGN & $0.01-0.05 \mathrm{~Hz}$ & Automatic \\
Group 2 & $200 \mathrm{~km}$ & KIS, KZK, YMZ & $0.01-0.05 \mathrm{~Hz}$ & Automatic \\
Group 3 & $600 \mathrm{~km}$ & GJM, TKD & $0.005-0.02 \mathrm{~Hz}$ & Manual \\
\hline
\end{tabular}

in teleseismic distances would be important for magnitude 8 earthquakes, however, it takes at least 3 hours to get the moment tensors (Dziewonski et al., 1981; Sipkin, 1982; Kawakatsu, 1995). Thus the AMTD method presented here using the regional distances would be necessary for early warning purposes.

Finally, we suspected that this kind of performance test by using synthetic waveforms is not perfect because of unexpected features sometimes seen in the natural observations. We therefore analyzed two magnitude seven earthquakes, the 1993 Hokkaido Nansei-oki ( $\mathrm{M}_{\mathrm{J}}$ 7.8) and the 1995 Kobe $\left(\mathrm{M}_{\mathrm{J}}\right.$ 7.2) earthquakes recorded at three stations that were operating before the FREESIA/KIBAN network was established.

\section{The Tokai Earthquake Model}

The "Tokai" earthquake hypothesis has been proposed by Ishibashi (1981) about 20 years ago, which was mainly based on the earthquake repeat cycle determined from historical documents. He also took into account the tectonics of this region as well as long term geodetic ( $~ 100$ years) and geomorphological observations. And he proposed a "Tokai" earthquake source model, we call the "Ishibashi model" (Fig. 3(b)), to help prepare local community for this earthquake.

Yoshioka et al. (1993) computed the backslip vector distribution along the Philippine Sea plate subduction zone by using geodetic observations such as leveling and triangular 

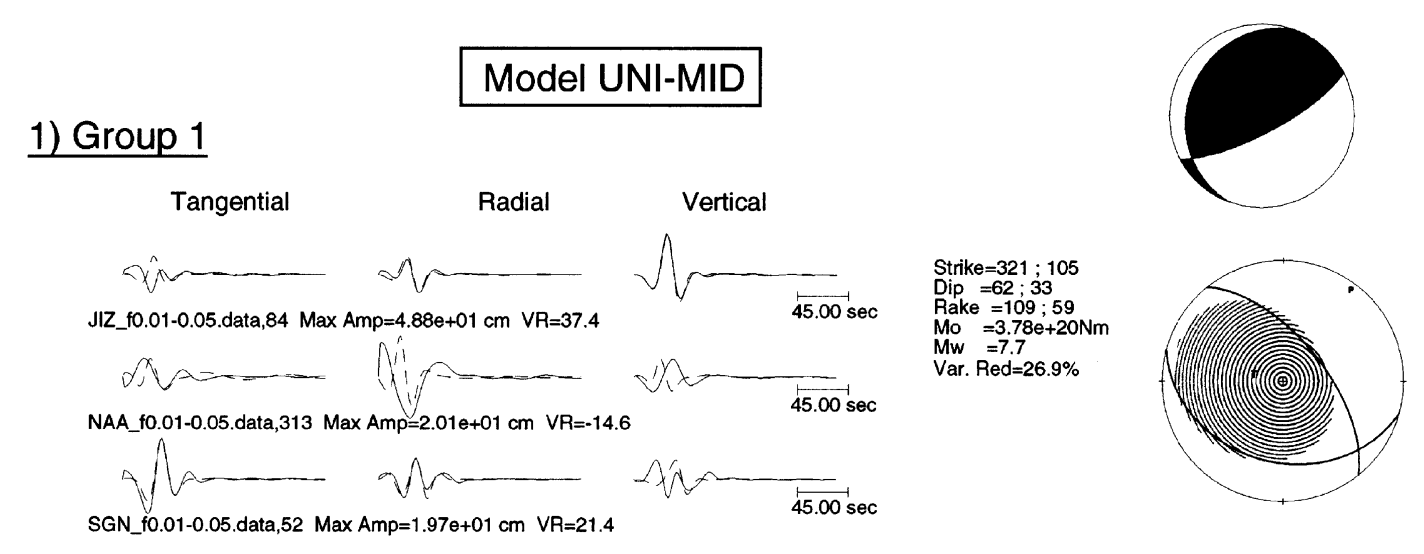

\section{2) Group 2}
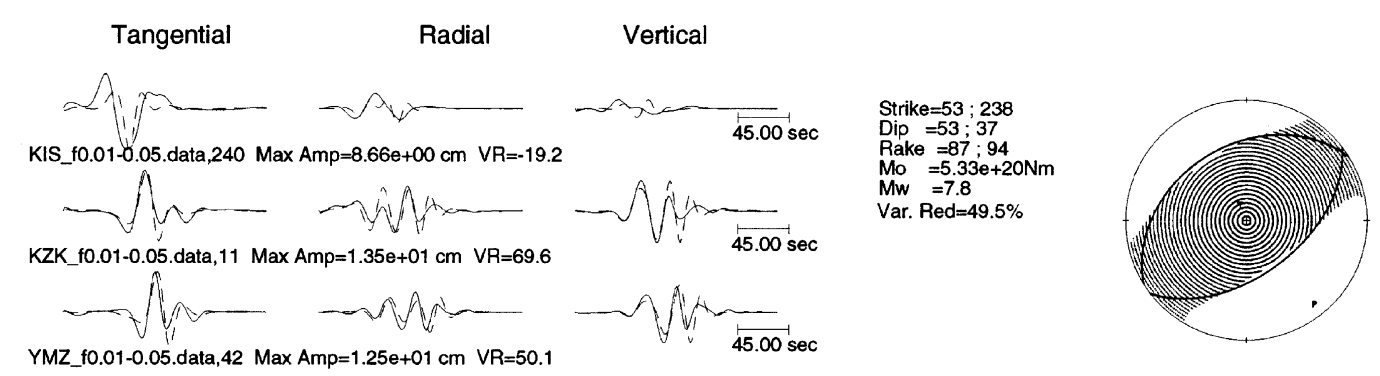

\section{3) Group 3}
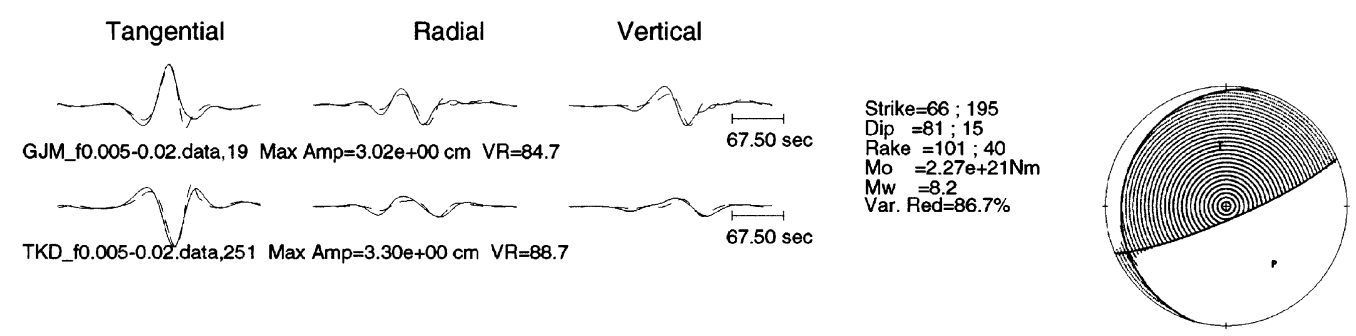

Fig. 4. Result for uniform slip model for bilateral rupture. Upper right focal mechanism is the assumed (true) solution. Three panels 1), 2) and 3) correspond to the dataset for Groups 1, 2 and 3, respectively. Left part of each panel, comparisons are shown between observed seismograms (computed for the assumed fault model) and estimated synthetics are shown with solid and broken lines, respectively. In middle part, obtained parameters are shown and in the right obtained moment tensor is shown in the right part.

Table 4. Estimated centroid depth for each model.

\begin{tabular}{lccc}
\hline & Group 1 & Group 2 & Group 3 \\
\hline UNI-MID & $20 \mathrm{~km}$ & $25 \mathrm{~km}$ & $20 \mathrm{~km}$ \\
UNI-NW & $25 \mathrm{~km}$ & $20 \mathrm{~km}$ & $20 \mathrm{~km}$ \\
HET-MID & $20 \mathrm{~km}$ & $15 \mathrm{~km}$ & $10 \mathrm{~km}$ \\
HET-NW & $20 \mathrm{~km}$ & $5 \mathrm{~km}$ & $20 \mathrm{~km}$ \\
SAG-UNI-MID & - & $25 \mathrm{~km}$ & $20 \mathrm{~km}$ \\
SAG-HET-NW & - & $25 \mathrm{~km}$ & $20 \mathrm{~km}$ \\
\hline
\end{tabular}

surveys and finite element modelling. His backslip distribution suggests a predicted rupture zone, expected slip distribution and direction for the future earthquake. Since backslip is defined as the difference between average slip in an earthquake cycle and ongoing slip after the major event on the subducting plate, backslip is considered to be a manifestation of a concentrated strain at the plate boundary for the future earthquake. His backslip distribution qualitatively coincides with the model proposed by Ishibashi (1981).

Matsumura (1997) found by compiling the focal mecha- 


\section{A) Model UNI-NW}
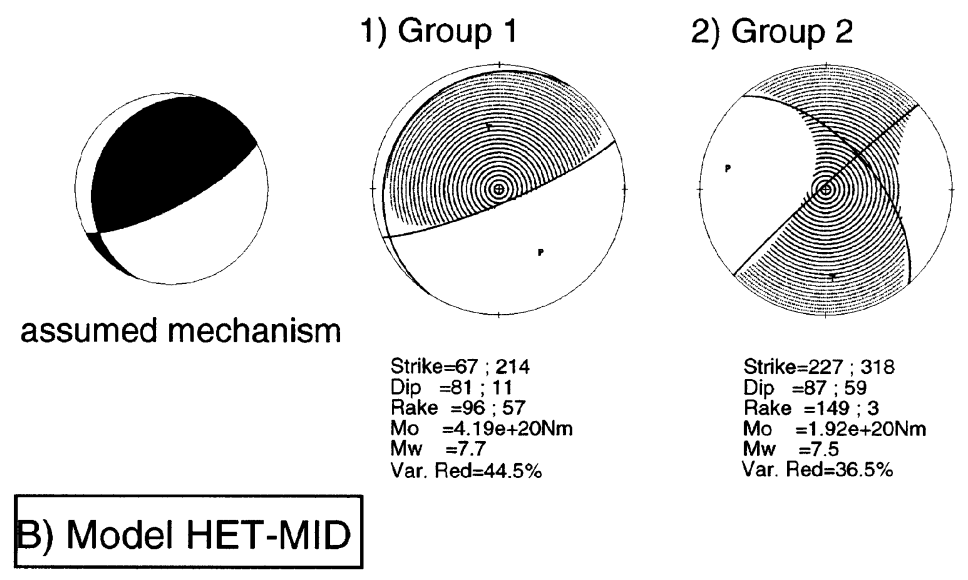

Strike $=227 ; 318$

Dip $=87 ; 59$
Rake $=149 ; 3$

Rake $=149 ; 3$
Mo $=1.92 \mathrm{e}+20 \mathrm{Nm}$

Mar. $\mathrm{Red}=36.5 \%$
Va

1) Group 1

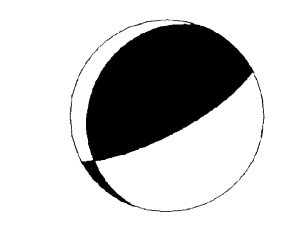

assumed mechanism

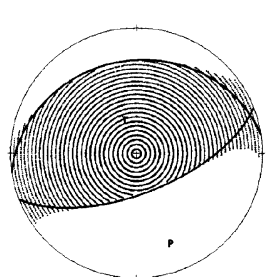

Strike $=68 ; 261$ Dip $=64 ; 27$
Rake $=84 ; 102$ Rake $=84 ; 102$
Mo $=4.79 \mathrm{e}+20 \mathrm{Nm}$ $\begin{array}{ll}\mathrm{Mo} & =4.79 \\ \mathrm{Mw} & =7.8\end{array}$ Var. Red $=52.0 \%$

\section{C) Model HET-NW}

1) Group 1

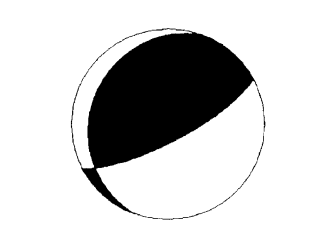

assumed mechanism
2) Group 2

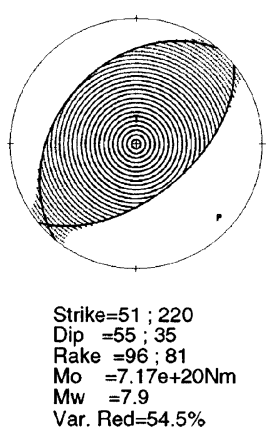

2) Group 2
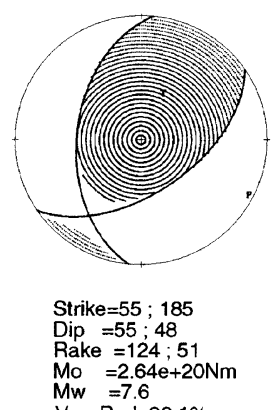

Mw $=7.6$
Var. Red $=26.1 \%$

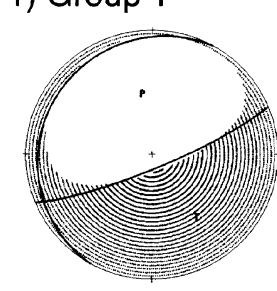

Strike $=67 ; 209$ Dip $=81 ; 12$
Rake $=-83 ;-12$ Rake $=-83 ;-128$
Mo $=6.93 \mathrm{e}+20 \mathrm{Nm}$ $\mathrm{Mw}=7.9$ Var. Red $=27.5 \%$
3) Group 3

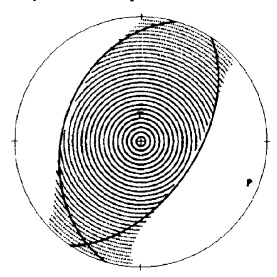

Strike=34 ; 196

Dip $=54 ; 37$

Rake $=101 ; 76$
Mo $=9.83 \mathrm{e}+20 \mathrm{Nm}$

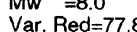

3) Group 3

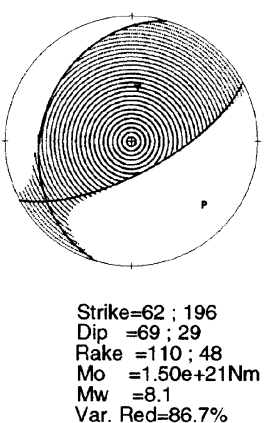

3) Group 3

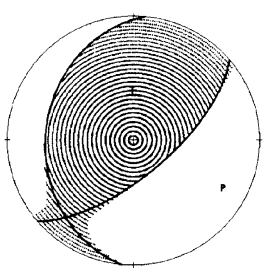

Strike $=49 ; \quad 185$

Dip $=67 ; 31$ Rake $=111 ; 50$
Mo $=9.50 e+20 \mathrm{Nm}$ $\mathrm{Mw}=8.0$ Var. Red $=71.7 \%$

Fig. 5. Results for A) uniform slip with north western hypocenter (Model UNI-NW), B) two asperity slip model with mid-bottom hypocenter (Model HET-MID), and C) two asperity model with north western hypocenter (Model HET-NW). Notations are the same as those in Fig. 4.

nisms of micro-earthquakes that a locked region of Philippine Sea plate subduction exists around the assumed fault area. The locked area by Matsumura (1997) corresponds to that estimated by Ishibashi (1981) and Yoshioka et al. (1993).

Another model has been recently proposed by Sagiya (1999) by analyzing recent GPS data to estimate the backslip vectors. We refer to this model as the "Sagiya Model" (Fig. 3(c)). Sagiya (1999) estimated a broader region with denser GPS data than that estimated by Yoshioka et al. (1993). His model corresponds to the "Sea of Enshu" earthquake that Ishibashi (1981) had proposed. We use models of both Ishibashi "Tokai" and Sagiya "Sea of Enshu" earthquakes to investigate the uncertainty of the fault mechanism on the performance of the AMTD.

For our Tokai simulations we constructed a fault with a length of $120 \mathrm{~km}$ and a width of $60 \mathrm{~km}$. This fault dimension was used in all of the Tokai mainshock simulations used in this paper. The orientation of the fault is (strike, dip, slip) $=\left(200^{\circ}, 20^{\circ}, 50^{\circ}\right)$ for the Ishibashi Model and $\left(255^{\circ}, 10^{\circ}\right.$, $150^{\circ}$ ) for the Sagiya Model. Total seismic moment in both models is assumed to be $2.18 \times 10^{21} \mathrm{Nm}$ in all simulations. Of course the hypocentral location of the future event as well as the slip distribution, rupture velocity, dislocation rise time are all unknown, and therefore we test the effects of these parameters with the goal of determining which control the quality of AMTD solutions. For simplicity our model only 


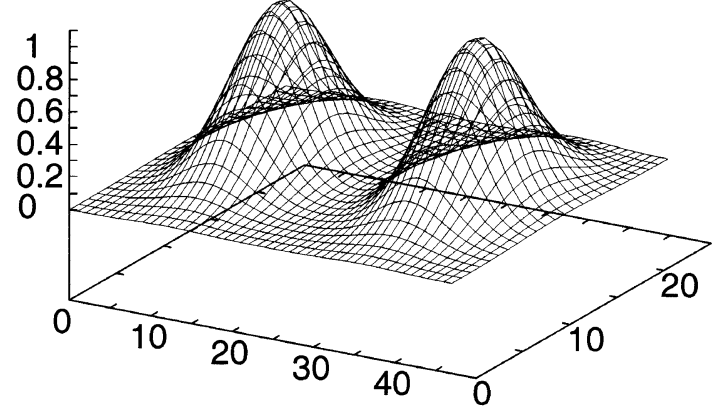

Fig. 6. Assumed slip distribution for heterogeneous slip model. Total amount of slip is scaled in order to make the total scalar moment release equals to the homogeneous slip case.

considers constant values of rupture velocity and dislocation rise time at every point on the fault. We also assume a point source depth as either of $5 \mathrm{~km}, 10 \mathrm{~km}, 15 \mathrm{~km}, 20 \mathrm{~km}$ and $25 \mathrm{~km}$ during the AMTD process. In Table 1 we summarized all the models we tested here. Hypocenter locations in this table (A-D) correspond to those in Figs. 3(b) and 3(c).

In all tests presented here, we calculated Green's functions using frequency wavenumber integration method (Saikia, 1994) assuming layered half space (Fukuyama et al., 1998). To obtain synthetic observation seismogram, we divided the fault surface into $1 \mathrm{~km}^{2}$ subfaults, we assumed source parameters (slip, rupture time and rise time) on each subfault, and then we summed up all the Green's functions convolved by the source parameters on each subfault. The assumed velocity structure is shown in Table 2 .

\section{Different Hypocenter Locations with Homoge- neous Slip}

The first test we performed was on hypocentral location keeping the distributed fault plane fixed in space. Two runs were performed in which hypocenters were located at the bottom center (A in Fig. 3(b)) and at the bottom of the north western edge of the fault (B in Fig. 3(b)). These two tests are sufficient to evaluate the effects of purely unilateral and bilateral ruptures, and focus on the directivity effect on the synthesized waveforms. Unilateral rupture propagation to the opposite direction would not be necessary to test because the rupture directivity effect becomes critical when the pulse width becomes broad. For these runs we assume a rupture velocity of $3 \mathrm{~km} / \mathrm{s}$, a constant dislocation rise time of 1 second, and uniform slip of $10 \mathrm{~m}$.

In Fig. 2, we show the computed displacement waveforms at TYM and NAA stations as an example. Note the similarity in these synthesized waveforms with those observed for Landers. The near-field static offsets for a Tokai event would be expected to be observed at distances of several hundred kilometers around the future fault plane. As Fig. 2 shows, both stations are located at the same hypocentral distance from the fault (Fig. 3(a)), yet displacement waveforms are very different. This difference is due to the radically different geometrical directivity focusing effects at these stations. TYM is in the direction of the updip rupture and consequently has a strong displacement pulse while NAA in the back az- imuth of the rupture tends to be dominated by the ramp type displacements of the near-field terms in the synthetics.

For this test as well as the following, we choose three different station groups each with their own frequency window as shown in Table 3. Group 1 (distance $=100 \mathrm{~km}$ ) would be the set of stations that would be used by AMTD as it is currently configured. Group 2 (distance $=200 \mathrm{~km}$ ) represents a small modification of the station selection program in the current code. Group 3 (distance $=600 \mathrm{~km}$ ) represents stations that are available to an operator for use in off-line analysis. 'Time shift adjustment' in Table 3 represents how to find the origin time of earthquake (zero offset of observed waveforms) since the rough origin time (in minutes) is used in the analysis. 'Automatic' indicates that zero-offset is estimated before the moment tensor inversion by taking the correlation between the Green's function and observation. 'Manual' shows that zero-offset is determined after the inversion by using grid search technique. These procedures are routinely used (Fukuyama et al., 1999).

The results of this test indicate that in the bilateral case, Group 1 fails to estimate the moment tensor in terms of both focal mechanism and scalar seismic moment (Fig. 4). However, for Group 2, the solution is much improved and the focal mechanism is very close to the exact mechanism however the scalar seismic moment is underestimated. For Group 3 we obtain a solution that is very close to the exact solution in terms of both focal mechanism and scalar seismic moment. In most cases focal depth is estimated at $20 \mathrm{~km}$, which seems to be reasonable (Table 4). Thus, for a bilateral rupture, using more distant stations results in acceptable results.

Figure $5 \mathrm{~A}$ shows the unilateral rupture case with uniform slip. In this test the fit to the synthetic data is worse than that for the bilateral case. Group 1 looks successful in this case, however, its variance reduction (index for waveform fit) was lower than $50 \%$. Group 2 also failed to estimate the correct moment tensor. These failures are due to the extreme broadening or narrowing of the $S$-wave pulses in the synthetic mainshock data due to the directivity effect. We found however that for this case the Group 3 inversion resulted in the most favorable solution.

\section{Heterogeneous Slip Distribution Test}

Next we examine the effect due to a heterogeneous slip distribution. In this case, we assume that the mainshock slip is segmented into two parts over the same fault area in the uniform slip case. The slip distribution used in this section is shown in Fig. 6. We have scaled the amount of slip in order to fit its scalar moment to that of the homogeneous case. In order to emphasize the directivity effect for the asperity, we assume a rupture velocity of $2.0 \mathrm{~km} / \mathrm{s}$ for the unilateral case while we assume $3.0 \mathrm{~km} / \mathrm{s}$ for the bilateral case (Table 1). Thus in the unilateral rupture there will be extreme azimuthal variation in wave focusing, while in the bilateral case the concentrated slip and fast rupture velocity results in short pulses. In both cases double $S$-wave pulses can be generated by the two asperities. As before we assume that the dislocation rise time is constant across the fault with a value of 1 second.

In Fig. 5B, we show the effect of this heterogeneous slip distribution. In this first case, we assume again that the rup- 


\section{A) Model SAG-UNI-MID}
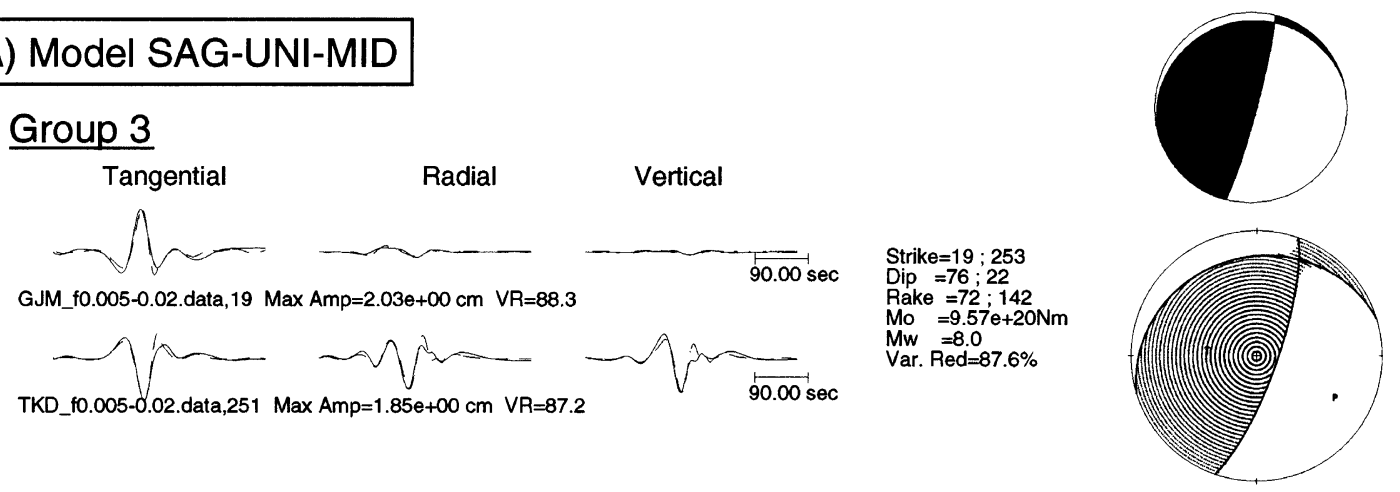

TKD_f0.005-0.02.data,251 Max Amp=1.85e+00 cm VR=87.2

\section{B) Model SAG-HET-NW}

\section{Group 3}
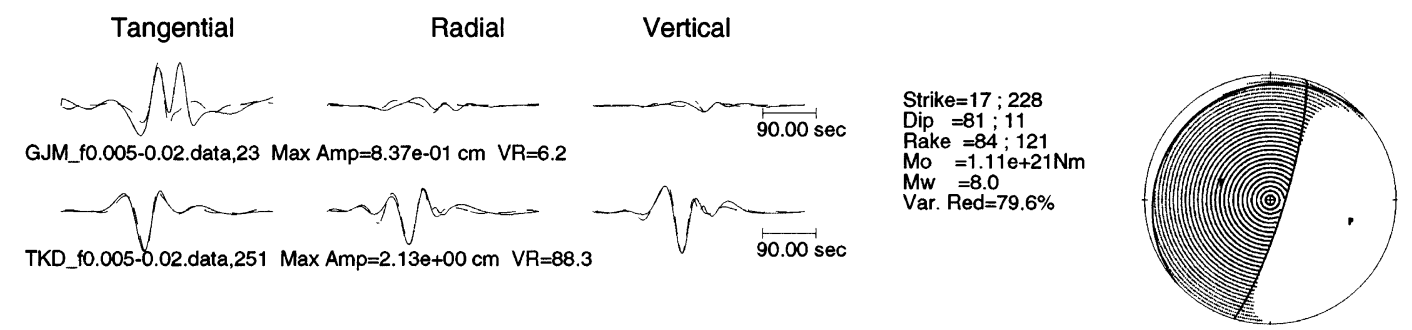

Fig. 7. Result for the Sagiya model. Upper panels shows the bilateral rupture and homogeneous slip case (Model SAG-UNI-MID) and lower panel shows the unilateral rupture with heterogeneous slip case (Model SAG-HET-NW). Other notations are the same as in Fig. 4.
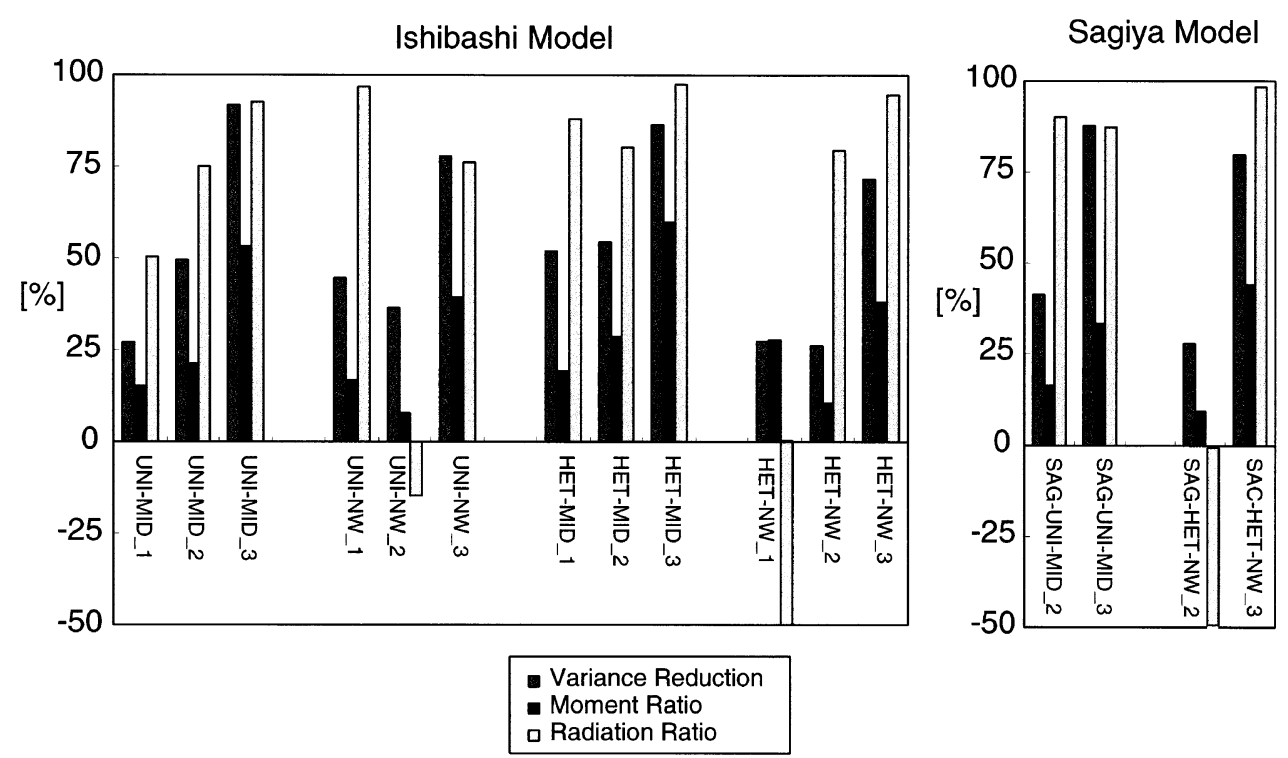

Fig. 8. Summarize the results for all computations. In each computation, variance reduction $(V R)$, scalar moment release ratio, and $P$-wave radiation pattern correlation $(P R)$ are shown. 'UNI-MID', 'UNI-NW', 'HET-MID', 'HET-NW', 'SAG-UNI-MID' and 'SAG-HET-NW' stand for uniform slip with mid bottom hypocenter model, uniform slip with north-west hypocenter model, heterogeneous slip with mid bottom hypocenter model, and heterogeneous slip with north-west hypocenter model for Ishibashi model and uniform slip with mid bottom hypocenter model and heterogeneous slip with north-west hypocenter model for Sagiya model, respectively. The last number stands for the Group. The unit of vertical axis is in percent.

ture starts at the middle bottom of the fault (A in Fig. 3(b)). Thus the rupture propagated bilaterally upward. The Group 1 inversions were not able to estimate the moment tensor correctly. Group 2 obtained a fairly good focal mechanism solution but still resulted in smaller scalar seismic moment. As before, Group 3 obtained the correct solution. The centroid depth is estimated at $10 \mathrm{~km}$, which is shallower than other cases (Table 4).

Next the unilateral rupture model with heterogeneous slip is tested (Fig. 5C). In this case, the observed waveform consists of two distinct wave trains each radiated from one of the two asperities. In every case the AMTD attempted to fit the 


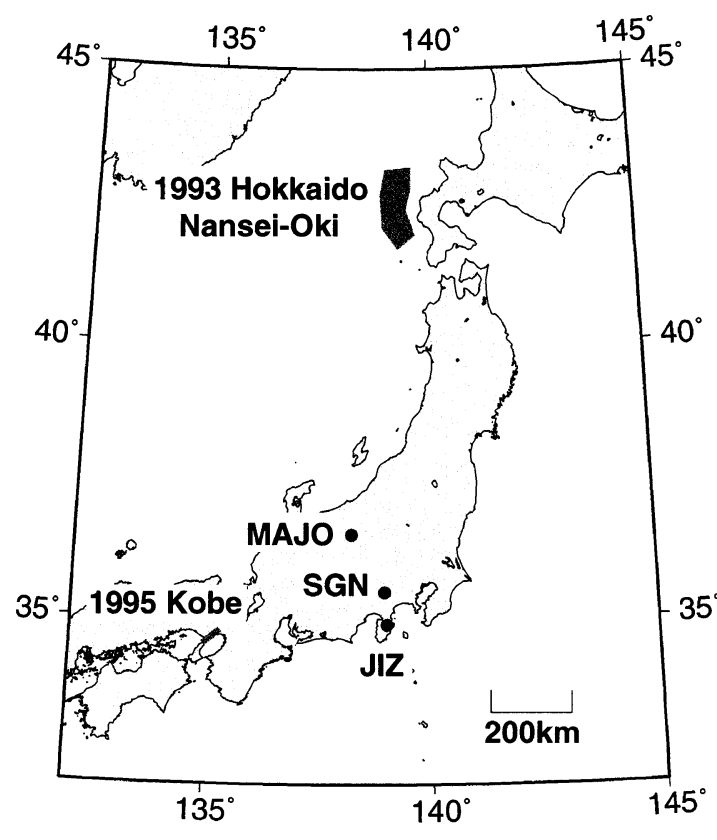

Fig. 9. Station distributions used for the analysis of the 1993 Hokkaido Nansei-oki earthquake and the 1995 Kobe earthquake.

first of the pulses, therefore only sensing a part of the total moment release. Moreover, in Groups 1 and 2, corner frequency of the earthquake is lower than the cut-off frequency of the waveform, seismic moment could be underestimated. It was initially surprising that for Groups 2 and 3, we could get better solutions than those in the unilateral homogeneous slip case. In retrospect this is due to the relatively short pulse width due to the concentrated nature of slip being better modeled by the simple point-source Green's functions that we employ in the AMTD inversion. The results of this test indicate that with some effort it is possible to obtain the moment tensor for a distributed slip event. It is important to note however that in these two cases the second asperity is completely ignored and if the focal mechanism of that asperity differed from the first it would be unknown unless it was determined manually by an analyst.

\section{Different Fault Mechanism and Location}

In this section we examine the Sagiya model of the Tokai earthquake. In this model the location and focal mechanism of the event are different however we use the same station distribution as before. Because of limited space we show only the results for the Group 3 inversions. In both unilateral and bilateral cases as well as the homogeneous slip and heterogeneous slip distribution cases, we obtained a better solution compared to the results using the Ishibashi model (Fig. 7). This is mainly because the directivity effect is more dominant in this test. For example, in the Sagiya model the rupture propagates toward the TKD station and the observed pulse becomes narrow. However, in the Ishibashi model, the rupture propagates away from the GJM station and the observed pulse becomes broad, which made the moment tensor inversion difficult. In both cases centroid depth is estimated at $20 \mathrm{~km}$ (Table 4), which looks reasonable.

\section{Summary of the Results of Synthetic Test}

All of the results are summarized in Fig. 8 in which we show three parameters (variance reduction, moment release ratio, and $P$-wave radiation ratio) from each inversion in order to evaluate the quality of the solution. Variance reduction $(V R)$, which indicates the fit between observed (synthetic Tokai data) and synthetics, is computed by the following equation:

$$
V R[\%]=100 \times \sum_{i} w_{i}\left(1-\frac{\int\left(s_{i}(t)-o_{i}(t)\right)^{2} d t}{\int o_{i}^{2}(t) d t}\right)
$$

where $s_{i}(t)$ and $o_{i}(t)$ are synthetic and observed seismograms, respectively at the $i$-th station. $w_{i}$ is a weight for summation which is proportional to the epicentral distance. Moment ratio is the scalar moment ratio between estimated moment release and the actual value assigned to the synthetic data. The $P$-wave radiation ratio $(P R)$, which is an index to measure the fit between two focal mechanisms, and is computed by the following equation:

$$
P R[\%]=100 \times \int_{0}^{2 \pi} \int_{-\pi / 2}^{\pi / 2} \frac{F^{e}(\theta, \phi) F^{o}(\theta, \phi)}{\left|F^{e}(\theta, \phi)\right|\left|F^{o}(\theta, \phi)\right|} d \theta d \phi
$$

where $F^{e}$ and $F^{o}$ are the estimated and assigned $P$-wave radiation patterns, respectively. $\phi$ and $\theta$ are azimuth and take-off angle, respectively.

As Fig. 8 shows, Groups 1 and 2 sometimes failed to estimated the correct solution, however with the Group 3 configuration we obtain reliable solutions in every case.

Since this method enables us to obtain the centroid depth information, we have compiled the best fit depths for each model (Table 4). In most cases depth is estimated at $20 \mathrm{~km}$, which is slightly deeper than that we assumed. This may depend on the narrow azimuthal coverage of stations. However, we found that we could estimate the centroid depth within a error of $\pm 5 \mathrm{~km}$.

\section{Application to the Past M7 Earthquakes}

In order to confirm the result obtained using synthetic waveforms, we have analyzed two dataset, the 1993 Hokkaido Nansei-oki earthquake (1993/07/12, 13:17(UT), 42.812N, $\left.139.133 \mathrm{E}, 25 \mathrm{~km}, \mathrm{M}_{\mathrm{J}} 7.8\right)$ and the 1995 Kobe earthquake (1995/01/16, 20:46 (UT), 34.593N, 135.035E, 18 km, MJ 7.2). We used three stations JIZ, SGN and MAJO for both earthquakes (Fig. 9). Their hypocentral distance is about $400 \mathrm{~km}$ for the Kobe earthquake and about $800 \mathrm{~km}$ for the Hokkaido earthquake.

For the Kobe earthquake, we could successfully obtained the focal mechanism (Fig. 9(a)) similar to those already obtained by many researchers (e.g. Kikuchi and Kanamori, 1997). In this analysis, we have used 0.01-0,05 Hz displacements data, that corresponds to the Group 2 case in the previous section. This result shows AMTD system can obtain reliable solution of magnitude seven earthquakes. In this computation, centroid depth is estimated at $17 \mathrm{~km}$, which is consistent with its hypocentral depth estimated by the $P$ - and $S$-wave onsets, however, it is slightly deeper than the centroid depth (e.g. Yoshida et al., 1996). 
A) 1995 Kobe Earthquake (MJ 7.2)

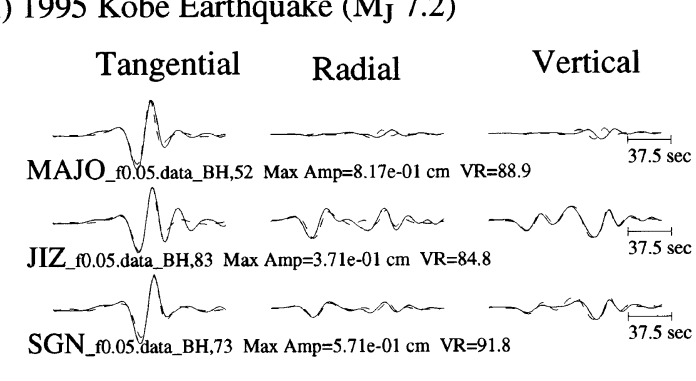

$$
0.01-0.05 \mathrm{~Hz} \sim 400 \mathrm{~km}
$$

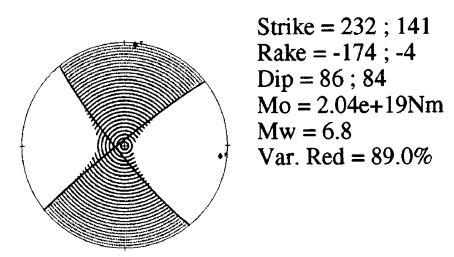

B) 1993 Hokkaido Nansei-oki Earthquake (MJ 7.8)
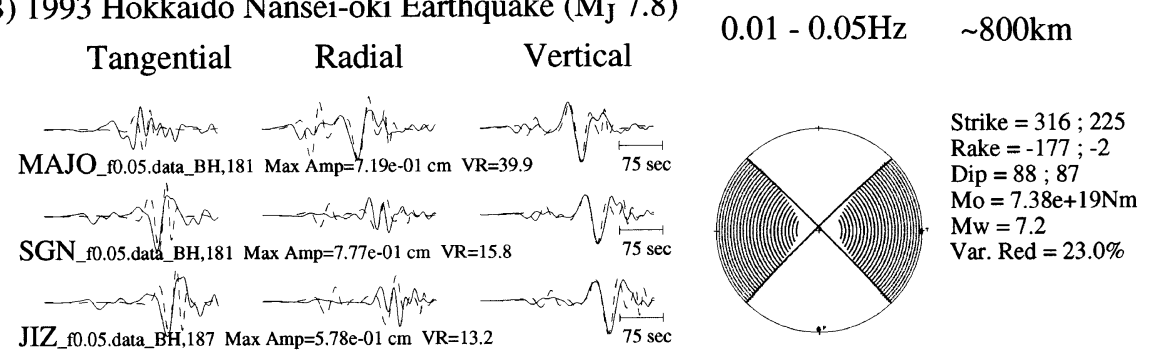

C) 1993 Hokkaido Nansei-oki Earthquake (MJ 7.8)
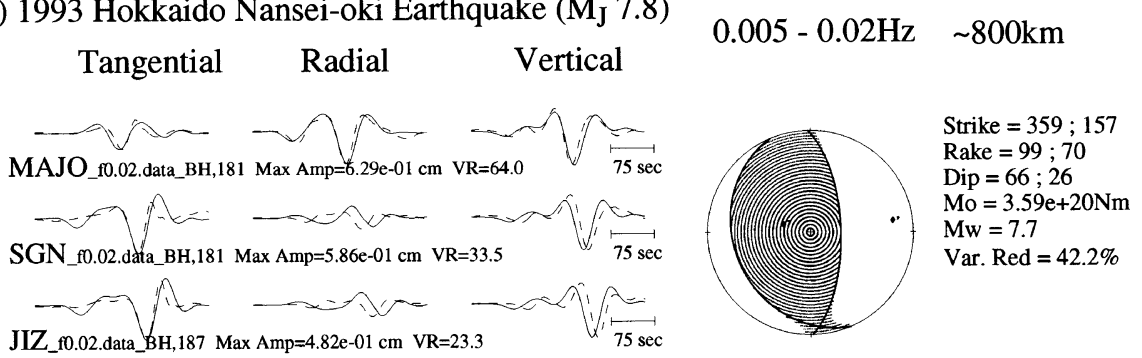

Fig. 10. Results of moment tensor analysis by using past real earthquakes. A) the result for the 1995 Kobe earthquakes with $0.01-0.05$ Hz frequency displacements. B) the result for the 1993 Hokkaido Nansei-oki earthquake with $0.01-0.05 \mathrm{~Hz}$ displacements. C) same as B) but using $0.005-0.02 \mathrm{~Hz}$ displacements. Other notations are same as in Fig. 4.

For the Hokkaido Nansei-oki earthquake, using the Group 2 condition $(0.01-0.05 \mathrm{~Hz}$ displacements) it fails to estimate the correct solution (Fig. 9(b)). However, if we use the Group 3 condition (0.005-0.02 Hz displacements), we have obtained a solution (Fig. 9(c)) similar to those already obtained (e.g. Mendoza and Fukuyama, 1996; Kuge et al., 1996). Thus we could say that for magnitude 8 earthquake, by using longer period displacement data we can obtain a stable and reliable solution. In this computation, centroid depth is estimated at $5 \mathrm{~km}$, which is slightly shallower than the centroid depth (Mendoza and Fukuyama, 1996).

\section{Conclusion}

We have investigated the performance of a regional distance, automated moment tensor determination (AMTD) system in the estimation of source parameters of large magnitude greater than 8 earthquakes. We have found that reliable results are possible if more distant stations and low frequencies are used. Both of these modifications to the procedure as currently implemented satisfy the point-source assumption for the large events. The centroid depth may be estimated within a certain level of error due to the insufficient station coverage. Of course at teleseismic distances satisfying the point-source requirements is relatively easy however the additional propagation delays introduced by considering teleseismic data sets would reduce the utility of the AMTD procedure in rapid response.

The tests in this paper were by no means exhaustive however they do address the critical issues of directivity focusing and homogeneous vs. heterogeneous slip in large earthquakes. The analysis of two large earthquakes indicates that the codes as they are currently implemented will perform satisfactorily for magnitude seven event. For larger earthquakes (magnitude eight) it will be necessary to perform an iterative inversion in which once an initial $\mathrm{M}_{\mathrm{W}}$ indicates that a large event has occurred data from more distant stations and in a lower pass band are utilized. This of course will delay the issuance of source parameter information due to the additional delay for the seismic waves to propagate to the more distant stations, and the additional iterative step. Alternatively or in parallel it is likely that a more complete representation of the finiteness of the source will be necessary to characterize these great earthquakes.

Acknowledgments. FREESIA broadband seismic network is supported by the NIED project titled 'Fundamental Research on Earthquake and Earth's Interior Anomaly'. KIBAN broadband seismic 
network is supported by the Science and Technology Agency under the cooperation of the Earthquake Research Council.

\section{References}

Dreger, D. S. and D. V. Helmberger, Broadband modeling of local earthquakes, Bull. Seismol. Soc. Am., 80, 1162-1179, 1990.

Dreger, D. S. and D. V. Helmberger, Source parameters of the Sierra Madre earthquake from regional and local body waves, Geophys. Res. Lett., 18, 2015-2018, 1991.

Dziewonski, A. M., T.-A. Chou, and J. H. Woodhouse, Determination of earthquake source parameters from waveform data for studies of global and regional seismicity, J. Geophys. Res., 86, 2825-2852, 1981.

Fukuyama, E., M. Ishida, S. Hori, S. Sekiguchi, and S. Watada, Broadband seismic observation conducted under the FREESIA Project, Rep. Nat'l Res. Inst. Earth Sci. Disas. Prev., 57, 23-31, 1996.

Fukuyama, E., M. Ishida, D. S. Dreger, and H. Kawai, Automated seismic moment tensor determination by using on-line broadband seismic waveforms, Zisin, 51, 149-156, 1998.

Fukuyama, E., M. Ishida, H. Horiuchi, H. Inoue, S. Hori, S. Sekiguchi, H. Kawai, and H. Murakami, NIED seismic moment tensor catalogue January 1998-December 1998, Technical Note of the National Research Institute for Earth Science and Disaster Prevention, 193, 1-35, 1999.

Ishibashi, K., Specification of a soon-to-occur seismic faulting in the Tokai district, central Japan, based upon seismotectonics, in Earthquake Prediction, Maurice Ewing Ser. 4, edited by D. W. Simpson and P. G. Richards, pp. 297-332, American Geophysical Union, Washington D. C., 1981.

Kawakatsu, H., Automated near-realtime CMT inversion, Geophys. Res. Lett., 22, 2569-2572, 1995.

Kikuchi, M. and H. Kanamori, Rupture process of the Kobe, Japan, earth- quake of Jan. 17, 1995, determined from teleseismic body waves, J. Phys. Earth, 44, 429-436, 1997.

Kuge, K., J. Zhang, and M. Kikuchi, The 12 July 1993 Hokkaido-NanseiOki, Japan, earthquake: Effects of source complexity on surface wave radiation, Bull. Seismol. Soc. Am., 86, 505-518, 1996.

Matsumura, S., Focal zone of a future Tokai earthquake inferred from the seismicity pattern around the plate interface, Tectonophys., 273, 271-291, 1997.

Mendoza, C. and E. Fukuyama, The July 12, 1993, Hokkaido-Nansei-Oki, Japan, earthquake: Coseismic slip pattern from strong-motion and teleseismic recordings, J. Geophys. Res., 101, 791-801, 1996.

Sagiya, T., Interplate coupling in the Tokai district, central Japan, deduced from continuous GPS data, Geophys. Res. Lett., 26, 2315-2318, 1999.

Saikia, C. K., Modified frequency-wavenumber algorithm for regional seismograms using Filon's quadrature: Modeling of $\mathrm{Lg}$ waves in eastern North America, Geophys. J. Int., 118, 142-158, 1994.

Sipkin, S. A., Estimation of earthquake source parameters by the inversion of waveform data: synthetic waveforms, Phys. Earth Planet. Inter, 30, 242-259, 1982.

Yoshida, S., K. Koketsu, B. Shibazaki, T. Sagiya, T. Kato, and Y. Yoshida, Joint inversion of near- and far-field waveforms and geodetic data for the rupture process of the 1995 Kobe earthquake, J. Phys. Earth, 44, 437-454, 1996.

Yoshioka, S., T. Yabuki, T. Sagiya, T. Tada, and M. Matsu'ura, Interplate coupling and relative plate motion in the Tokai district, central Japan, deduced from geodetic data inversion using ABIC, Geophys. J. Int., 113, 607-621, 1993.

E. Fukuyama (e-mail: fuku@bosai.go.jp) and D. S. Dreger 